\title{
Methodology on Empirical Study in Determining Critical Energy Efficiency Factors for Building Structural Components
}

\author{
Saeed Balubaid ${ }^{\#}$, Rosli Mohammed Zin ${ }^{*}$, Shaik Hussein Mydin ${ }^{\#}$ \\ ${ }^{\#}$ Faculty of Engineering, Hadramout University, Mukalla, Hadhramout, Yemen \\ Email: b2003alubaid@yahoo.com \\ "Faculty of Civil Engineering, Universiti Teknologi Malaysia, 81310 UTM Johor Bahru, Johor, Malaysia \\ Email: roslizin123@yahoo.com \\ ${ }^{\#}$ AEC prima Sdn Bhd Penang, Penang, Malaysia. \\ Email: shaikhussein@ymail.com
}

\begin{abstract}
Making a decision to select building structural components is one of the sustainable construction keys. Extensive reviews of the literature revealed that despite various studies being carried out focusing on the selection of building component alternatives, it was found that none have focused on the selection of building component alternatives based on multiple energy efficiency criteria. In addressing the research gap, this study is conducted with the aim to identify the energy efficiency factors for a selection building structural component. A quantitative method research design was adopted through questionnaire surveys. The population of the study selected was engineers registered with the Board of Engineers Malaysia (BEM) in the year 2015. The Simple Random Sample (SRS) technique was adopted to select samples, and 263 samples were selected. The collected data were analyzed using descriptive analysis and Principal Component Analysis (PCA). The outcome of these analyses has resulted in the identification of two main factors which consists of eight energy efficiency criteria. The results of this study are expected to be beneficial in developing a tool to assist the decision-makers in selecting the appropriate energy efficient building structural systems.
\end{abstract}

Keywords—decision making; building component; energy efficiency; selection building structural component.

\section{INTRODUCTION}

Researchers have paid considerable attention to developing, validating and testing models of a decision making to select building structural components (e.g., walls, beams, floors, staircases, etc.). This is because of the availability of several building structural components having different performances and thus different impacts on the decision making [1-2].

Previous studies have addressed several aspects of decision making for selecting the appropriate building design related to the environment and sustainability issues. This selection includes;

(1) to select the buildable building structural components [3], [4],

(2) to select the sustainable building structural components [5], [6], and

(3) to select low-cost green building structural components [7].
On the other hand, however, decision making to select building structural components involves numerous unexplored dimensions, which recently have attracted several research attention in many other disciplines [8]. Some of these unexplored dimensions are the selection of energy efficient building structural components, which appears to be significant and worthy of exploration in the context of decision making to select building structural components. Also, previous empirical research has focused primarily on the selection of building structural components. Very little research has been done on the selection of energy efficient aspect.

An investigation of this issue plays a significant role in reducing energy consumption. Fifty percent embodied the energy of construction building materials could be reduced through the proper selection of building structural materials during the design phase [9]. Therefore, designers are encouraged to take into their in-depth consideration a proper design decision from the point of the building components selection. The design decision should be incorporated into 
energy consumption considerations throughout the design stages. Consequently, this may help to reduce the building's adverse effects on the global warming during its lifecycle.

This study aims to extend the selection of building structural components process by addressing the gaps in energy practical aspect. The study investigates the critical energy efficiency factors for the selection of building structural component. The selection of building components particularly the structural components directly affects the level of energy consumption throughout building life cycle. Several studies have explored the effects of the building structural components choice on the building lifecycle process.

The choice of building component affects the embodied energy as highlighted by [10]. It was concluded that $17 \%$ could reduce embodied energy through proper decisions of reducible structural material waste, the recyclable structural material, enhanced maintenance process as well as enhanced demolition process [10]. The energy consumption associated with the on-site building construction was investigated by [11]. He shows that the steel structure consumes the low energy throughout construction process than the concrete structure. This difference is occurred due to two factors namely enhanced transportation process and enhanced construction process.

The effect of building components choice about thermal mass on the operational energy for space heating was investigated by [12], [13]. They show that the concrete building frame had lower energy demand $(0.5-2.4 \%)$ than the wood frame. This is due to the enhanced thermal mass of the concrete frame envelope than the wood frame.

Even though there have been little studies which carried out related to the end of building life stage [13], the recycling building components have been emphasized as a significant factor in decreasing the life cycle energy of building [12]. For instance, [14] highlighted that the potential of recycling building material is $18 \%$ and $29 \%$ regarding Greenhouse Gas (GHG) emissions and lifecycle energy respectively. According to [15] who highlighted that up to $24 \%$ of embodied CO2 emissions can be reduced with the use of recycled building materials.

A comparative study using questionnaire survey with construction experts were conducted by [16] to evaluate the construction methods based on sustainability criteria. They found that Reducible organic material waste and Recyclable structural material definitely contributes to a reduction in energy consumption. They concluded that prefabrication results in less energy consumption impact than the conventional construction method.

The effect of building components choice in reducing embodied energy has been investigated by [17]. They found some options to reduce the embodied energy including reducible structural material waste, recyclable structural material, localizing the use of materials, and enhanced transportation process.

Seven principles of the sustainable building which related to the environment as well as energy consumption impact were highlighted by [18]. These criteria are reusable structural material, recyclable structural material, enhanced maintenance process, enhanced production process, enhanced thermal mass, enhanced construction process and enhanced transportation process,

The embodied energy of a precast building system and a conventional in-situ building system has been compared by [19]. They found that total embodied energy of the precast building system is $19 \%$ less than the conventional building. This is due to an enhanced production process, enhanced transportation process and enhanced construction process.

Recently, there has been an increasing amount of literature on energy consumption about the building component alternatives. Table 1 summarized the proposed selection energy efficiency criteria concerning building structural systems suggested by the literature.

TABLE I

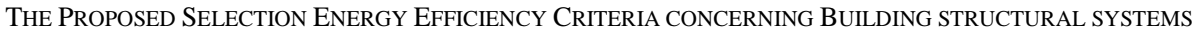

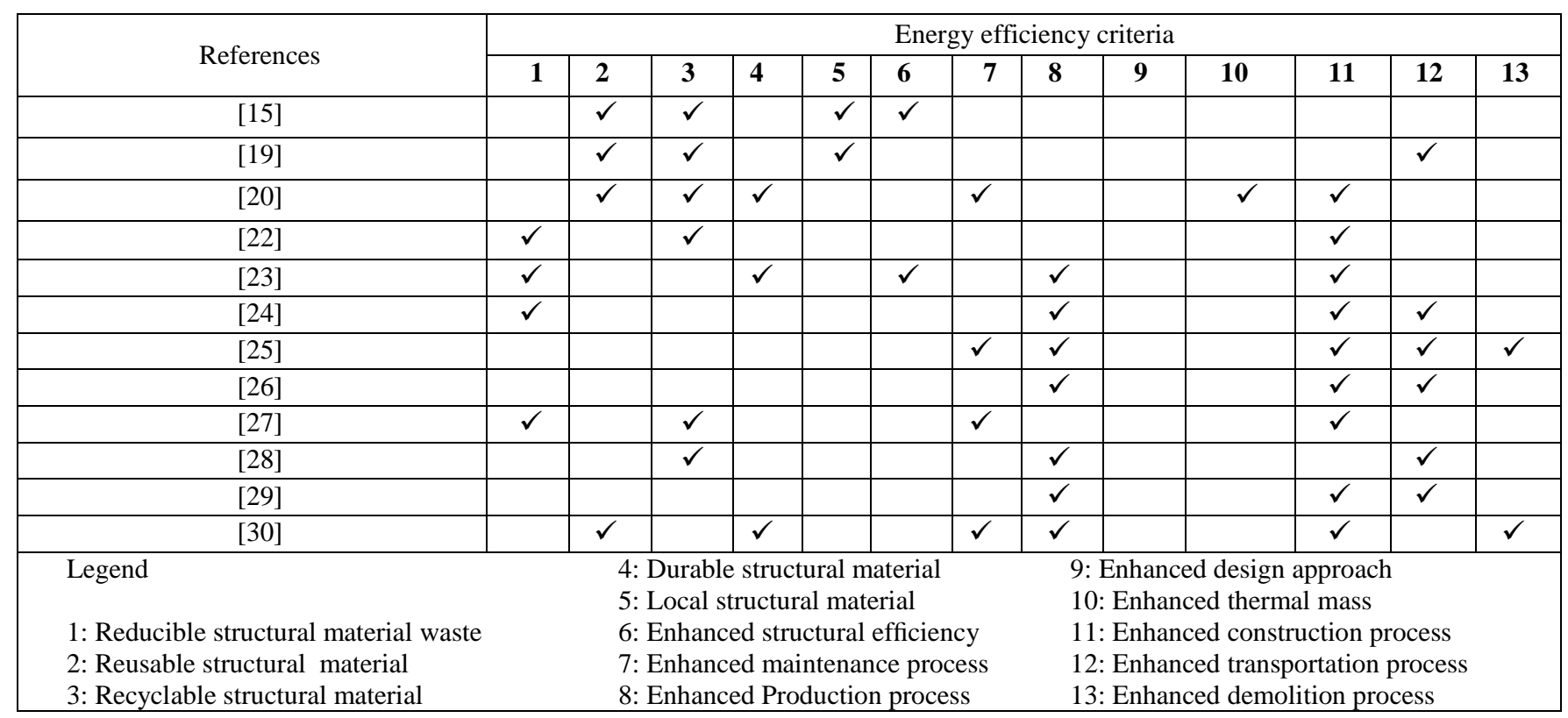




\section{MATERIAL AND METHOD}

Data were obtained through questionnaire surveys. The questionnaire survey involved five main steps, namely drafting of a questionnaire survey, piloting the questionnaire, sampling design, distributing the questionnaire, and analyzing the questionnaire as shown by a flow chart given in Figure 1. Each step is presented and explained in the following subsections.

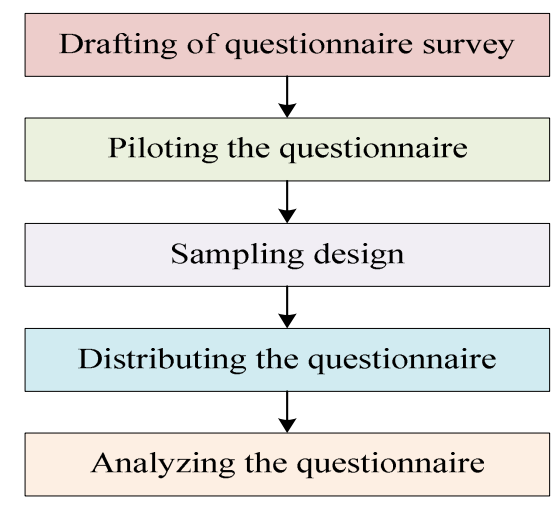

Fig. 1 Questionnaire Survey Development steps

\section{A. Drafting of Questionnaire Survey}

The questionnaire comprised of two sections (A\&B) as shown in Fig. 2. Section $\mathrm{A}$ is focused on exploring the background of the respondent (demographic questions). This section is concern about the location, type of organization, designation/role, work experience, and the awareness level. Meanwhile, section B of the questionnaire is focused on identifying the critical energy efficiency criteria of common building structural systems. Two types of questions including close-ended and open-ended questions were prepared in section B. The close-ended questions where the respondents whose responsibility is to rank a prescribed list of energy efficiency criteria. The respondents were asked to rate thirteen-energy efficiency criteria using the Likert fivepoint scale. The open-ended questions allowed respondents to add and rank further energy efficiency criteria which were not included in the prescribed list. The Likert-type scale comprising the following items:

1 = Low importance,

$2=$ Slightly importance,

$3=$ Neutral,

Four = Moderately importance, and

$5=$ Very importance.

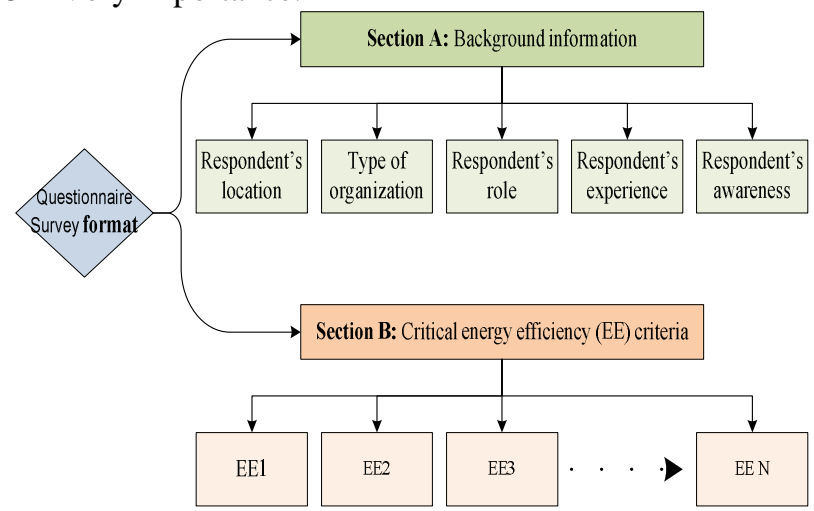

Fig. 2 Investigative Questions of the Questionnaire Survey

\section{B. Piloting the Questionnaire}

The pilot questionnaire was carried out in August 2015 to determine the suitability and comprehensibility of the proposed criteria. A sample size of 25 respondents was considered to conduct a pilot study as recommended by [29] for developing a quantitative instrument. The pilot questionnaire feedbacks were analyzed using the Statistical Package for Social Science (SPSS 20) software. Data obtained from the pilot questionnaire survey were analyzed using several statistical tests to confirm the reliability and suitability of the data, which include content validation and reliability tests.

\section{Sampling Design}

In the survey sampling design is used as particular component concerning the questionnaire. It is used to select the respondents to the questions from among the population. Probability sampling strategy was selected for the questionnaire survey based on the recommendation of [30]. The process of probability sampling consists of three tasks, firstly, identifying a suitable study sampling frame. Secondly, deciding on suitable sample size. Lastly, selecting the appropriate sampling technique within the selective the sample. The three processes of probability sampling are explained in following.

\section{1) Identifying a Suitable Sampling Frame}

This task is used to identify a suitable sampling frame for the targeted population (a target population is a group of respondents who can answer the particular question). The procedure carried out in this task is done by identifying all civil engineers registered with the Board of Engineers Malaysia (BEM) database. Based on the BEM database, 76,653 engineers are registered from all disciplines [31]. After careful sorting, it was realized that the number of civil engineering available among 76,653 registered engineers are 19613 professional Civil engineers.

\section{2) Deciding a Suitable Sample Size}

Deciding on a suitable sample size task is used to decide the sample size from the target population. In this task, the sample size is determined according to Kish's equations in [32] which are presented as Equation (1\&2). According to Equation (1\&2), the selected margin of error appeared as $6 \%$ within $95 \%$ confidence level as it is tabulated in TABLE II. As a result of equation ( $1 \& 2)$, the minimum recommended sample size of the response to this survey is 263 professional engineers.

$$
\mathrm{n}^{\prime}=\frac{S^{2}}{V^{2}}
$$

$$
n=\frac{n^{\prime}}{1+\left(\frac{n^{\prime}}{N}\right)}=\frac{\frac{(0.5)^{2}}{(0.031)^{2}}}{1+\left[\frac{(0.5)^{2}}{\frac{(0.031)^{2}}{19613}}\right]}=263
$$

Where,

$n^{\prime}=$ sample size from an infinite population

$\mathrm{S} 2=$ variance of the population elements $=\mathrm{P}(1-\mathrm{P})=$ $0.5(1-0.5)=(0.5) 2$ 


$$
\begin{aligned}
& \mathrm{V}=\text { standard error of sampling population }(6 \% \text { for this } \\
& \text { study })=\frac{0.06}{1}=0.031 \\
& \mathrm{n}=\text { sample size from a finite population } \\
& \mathrm{N}=\text { total population } \\
& \text { Since } \mathrm{r}=0.06 \text { and } \mathrm{t}=1.960 \text { at the } 95 \% \text { confidence level }
\end{aligned}
$$

TABLE II

Most COMMONLy USED T VALUES

\begin{tabular}{|c|c|}
\hline Confidence Level (\%) & Associated Z value \\
\hline 90 & 1.645 \\
\hline 95 & 1.960 \\
\hline 99 & 2.575 \\
\hline
\end{tabular}

\section{3) Selecting the Appropriate Sampling Technique}

Selecting the appropriate sampling technique task is used to select the respondents within the targeted population. To select the respondents from the targeted population, five types of the probability sampling techniques are presented in general namely Systematic Random, Simple Random, Stratified Random, Multi-Stage, and Cluster. From among these all techniques, the simple random sampling technique is most appropriate sampling technique used due to its accuracy and accessibility to the list of the target population. Based on accuracy and accessibility of this task, it is preferred to use a simple random sample technique.

\section{Distributing the Questionnaire}

Based on the result of the pilot questionnaire analysis, the questionnaire was taken through a process of complete revision of the set of the questions to make the questions more comprehensive. The questions were improved based on a comprehensive set of energy efficiency criteria, which is developed from the literature review as well as feedback received from the respondents concerning questionnaire pilot test.

The questionnaire was distributed based on various methods, such as sending questionnaire form manually, mailing, emailing and online survey site. Four hundred (400) questionnaire forms were successfully distributed to professional construction engineers in various states of Malaysia. Out of 400 distributed questionnaire forms, only two hundred and seventy-two (272) were successfully returned to the researcher, which represent $62 \%$ of response rate. Out of the 272 returned questionnaire forms, 23 of them were incomplete. Therefore, the valid questionnaire forms considered for analyzing the questionnaire in this study were taken as 249 questionnaire forms only.

\section{E. Questionnaire Analysis}

Questionnaire analysis is the type of analysis carried out to produce the result of the questionnaire. Various steps were conducted under this task to analyze the collected data from the questionnaire survey. This is done by using the Statistical Package for Social Science software (SPSS 20). The analysis procedure comprises of cleaning the data, testing the central tendency, testing the dispersion, frequency analysis, cross-tabulation analysis, and Principal Component Analysis (PCA). Every statistical test is explained as follow.

\section{1) Cleaning the Data}

Cleaning the questionnaire survey data was carried out using descriptive analysis to explore unusual data or existed errors present in the questionnaire forms. The descriptive analysis process aims at inspecting the data for values that are outside the accepted value range. This analysis aids to clean the data from obvious keystroke errors or missing data.

\section{2) Testing the Central Tendency}

Testing the central tendency is a method to examine the tendency of the respondents to respond to the set questions give to them. The three main ways of measuring the central tendency mostly used in research are mean, median, and mode. The most commonly used tendency is mean value analysis according to [33]. The descriptive analysis was performed on all data received from respondent's feedbacks using mean value analysis (average). The mean value of each question equivalent to 4.00 or above were considered as necessary for further analysis for Analytical Hierarchy Process (AHP) model development, while a mean value below 4.00 was eliminated from AHP model development.

\section{3) Testing the Dispersion}

There are two main ways for measuring the dispersion mostly used in research, namely Standard Deviation (SD) and coefficient of variation. The SD helps in describing and comparing the extent by which values differ from the mean. SD shows normality of the data distribution. Standard Deviation (SD) of all dataset was carried out for measuring the dispersion.

\section{4) Frequency Analysis}

Frequency distribution analysis is the best way of summarising and exploring the data from an individual variable. For categorical data, the frequency distribution table which is produced by SPSS software summarizes the number of cases in each category as suggested by [30].

The first section of the questionnaire (demographic) consists of categorical data. The demographic profile consists of several questions such as the location, the role working experience, the level of awareness, and level of participation. Therefore, frequency distribution was employed for summarising and exploring the certain demographic questions.

\section{5) Principal Component Analysis (PCA)}

PCA is used to help in reducing several variables into a smaller set of components according to their correlation [36, 37]. The principal component analysis was carried out in three sequence steps, namely assessing the suitability for PCA, extracting of the components, and rotating of the components.

\section{RESULT AND DISCUSSION}

The results and findings of questionnaire survey are presented in the following subsections.

\section{A. Section A: Demographic Profile}

The demographic profile of respondents were categorized into five items; location, type of organization, designation/role, work experience, and the awareness level. 
The demographic profile results of the responses are indicated in both numeric terms (frequency) and percentage (\%). Every demographic profile is described in the following subsections.

\section{1) Location}

Fig. 3 shows the distribution of respondents' location. It demonstrates that a total of $88 \%$ of the respondents comes from four states in Malaysia, namely Johor, Federal Territory, Penang, and Malacca. 201 out of the 249 respondents comes from these four states.

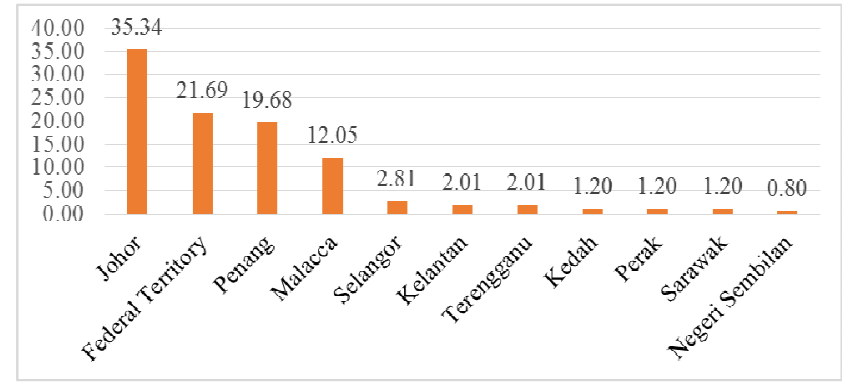

Fig. 3 Location of the Respondents

\section{2) Classification of Respondents}

Consultant, Client, and Academicians play a major influence in this research with a cumulative percentage of more than $70 \%$ as shown in Fig. 4.

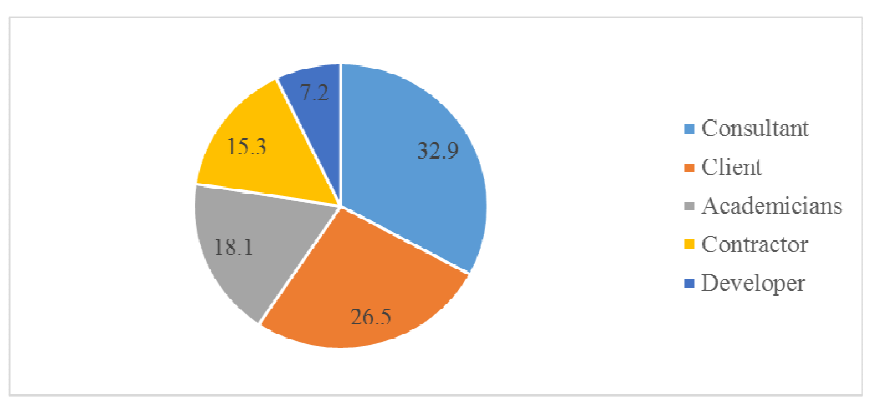

Fig. 4 Classification of Respondents

\section{3) Designation/Role}

Fig. 5 Designation of Respondents, it shows that Civil Engineers and Project Manager plays major influences in this research with a cumulative percentage of more than $85 \%$.

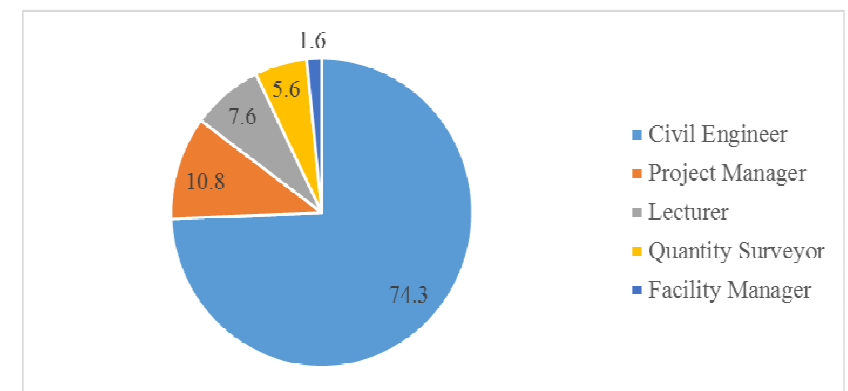

Fig. 5 Designation of Respondents

\section{4) Work Experience}

From Fig. 6, it can be seen that more than $65 \%$ of respondents had reasonable experience in the construction industry for more than ten years. The work experience of the respondents is reasonably acceptable. Therefore, respondent's opinions which obtained in this survey can be considered as reliable.

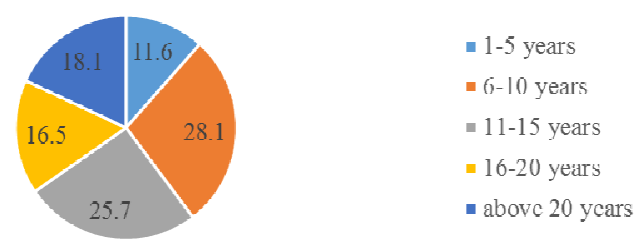

Fig. 6 Work Experience of Respondents

\section{5) Awareness Level}

From Fig. 7 it can be seen that more than $73 \%$ of respondents are aware of energy efficiency practice. The awareness level of the respondents is quite acceptable. Therefore, opinions obtained through this survey can be regarded as credible.

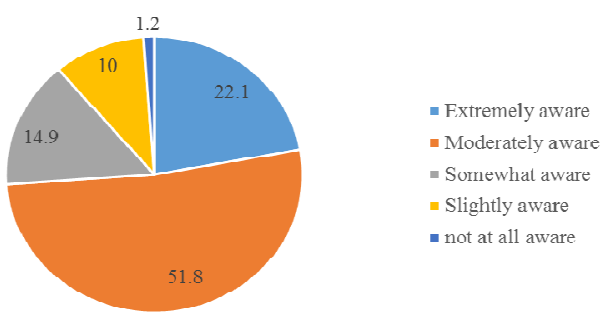

Fig. 7 Awareness Level of Respondent

\section{B. Section B: Energy Efficiency Criteria}

The questionnaire tried to analyze the 13 identified criteria one by one through several descriptive statistical analysis. This includes (i) reliability test using Cronbach Alpha ( $\alpha$ ), (ii) Mean Value and (iii) Principal Component Analysis (PCA). The descriptive statistical analyses of section $\mathrm{B}$ of questionnaire survey are presented in the section 1) to 3) below.

\section{1) Reliability Test}

TABLE indicates the summary of Cronbach's Alpha values for all thirteen criteria. The outcomes of the questionnaire analysis show a Mean $=52.73$, Variance $=37.97$, and Standard Deviation $=6.162$. The outcomes correspond to Cronbach's Alpha coefficient of 0.871 . Whereas, the 'rule of thumb' (accepted internal reliability level) of Cronbach's Alpha coefficient $\alpha \geq 0.70$. Therefore, the questionnaire items are reliable.

TABLE III

THE SUMMARY OF CRONBACH's ALPHA

\begin{tabular}{|c|c|c|c|}
\hline Mean & $\begin{array}{l}\text { Std. } \\
\text { Deviation }\end{array}$ & $\begin{array}{l}\text { Cronbach's } \\
\text { Alpha }\end{array}$ & N of Components \\
\hline 52.73 & 6.162 & .871 & 13 \\
\hline
\end{tabular}

2) Mean Value Analysis

To simplify the decision-making framework, only the criteria that obtained mean value equivalent to or above 4.00 were considered in decision-making framework. Nine energy efficiency criteria were rated as extremely important with mean value above 4.00 which are Enhanced thermal mass (P10), Enhanced design Approach (P9), Enhanced 
production process (P8), Recyclable structural material (P3), Reusable structural material (P2), Enhanced construction process (P11), Enhanced structural efficiency (P6), Reducible structural material (P1), Durable structural material (P4) as shown in Fig. 8.

Surprisingly, Enhanced demolition process (P13) and Enhanced transportation energy (P12) were not considered as a key criterion in the decision-making framework. This finding reinforced the argument of [38], which concluded that demolition process and transportation energy were insignificant when even more improvements would not lead to any noticeable energy reductions of building life-cycle.

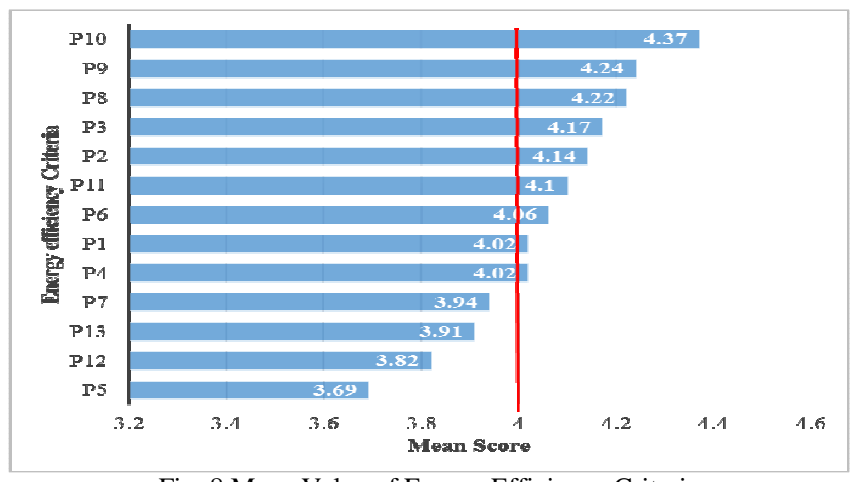

Fig. 8 Mean Value of Energy Efficiency Criteria

\section{3) Principal Component Analysis}

PCA was employed to reduce the set of variables into a smaller number of set variables according to their correlation. The PCA technique was carried out using the important nine (9) identified criteria to recognize the underlying the criteria structure. PCA was carried out in three sequence steps, namely (i) assessing the suitability of variables for PCA, (ii) extracting of principal components, and (iii) rotating the factors. Every step results are presented in the following sections:

\section{- Assessing the Suitability of Variables for PCA}

In this step, two main tests were carried out to determine the suitability of the variables in the dataset for PCA namely Kaiser-Meyer-Olkin (KMO), and Bartlett's test of Sphericity. KMO measurements were calculated to verify the sampling adequacy for the analysis. It has been suggested that recommended value of $\mathrm{KMO} \geq 0.60$ may be used to confirm the sampling adequacy [39-41]. In the questionnaire, the KMO value is 0.828 as shown in Table . Therefore, the questionnaire items are suitable to conduct PCA. Meanwhile, Bartlett's test of Sphericity $\chi^{2}$ was carried out to check the data are not identical. Researchers have suggested that Sphericity $\chi^{2}$ is considered to be statistically significant at $\mathrm{P}<0.05[39,40]$. In this questionnaire, Bartlett's Test of Sphericity $\chi^{2}$ is 0.000 as shown in Table . Therefore, the result shows that the correlations between criteria were sufficiently supported to conduct PCA. Consequently, the criteria may be grouped into a smaller set of factors.
KMO AND BARTLETT'S TEST

\begin{tabular}{|l|l|l|}
\hline \multicolumn{2}{|c|}{$\begin{array}{c}\text { Kaiser-Meyer-Olkin Measure of } \\
\text { Sampling Adequacy }\end{array}$} & $\mathbf{. 8 2 8}$ \\
\hline \multirow{3}{*}{$\begin{array}{l}\text { Bartlett's Test of } \\
\text { Sphericity }\end{array}$} & Approx. Chi-Square & 983.353 \\
\cline { 2 - 3 } & Df & 36 \\
\cline { 2 - 3 } & Sig. & 0.000 \\
\hline
\end{tabular}

\section{- Extraction of Principal Components}

The Principal Component was extracted using nine (9) identified criteria to extract the number of factors. The correlation matrix of essential nine (9) identified criteria indicates that all identified criteria are strongly correlated with each other except the criteria labeled 9. Therefore, the weak criteria were deleted, and then the Principal Component was extracted in the second round using the critical eight (8) identified criteria. Also, the Kaiser's criterion (eigenvalue rule) of the identified eight (8) criteria variance was determined to decide the number of important components. This step to extract the preliminary factors. Table 5 shows the eigenvalues of the components with a value greater than 1 . It can see that there are only two components with eigenvalues greater than 1 . The set of components are explaining about $48.8 \%$, and $18 \%$ of the variance respectively. Also, they represent $66.8 \%$ of the total cumulative variance.

TABLE V

TOTAL VARIANCE EXPLAINED

\begin{tabular}{|c|c|c|c|c|c|c|c|}
\hline \multirow{2}{*}{ 苞 } & \multicolumn{3}{|c|}{ Initial Eigenvalues } & \multicolumn{3}{|c|}{$\begin{array}{l}\text { Extraction Sums of } \\
\text { Squared Loadings }\end{array}$} & \multirow[t]{2}{*}{$\begin{array}{l}\text { Rotation } \\
\text { Sums of } \\
\text { Squared } \\
\text { Loadings }\end{array}$} \\
\hline & 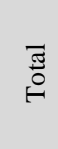 & 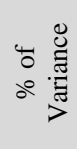 & $\underbrace{\stackrel{\Xi}{\Xi}}_{\Xi}$ & సี & 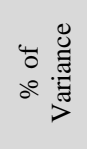 & 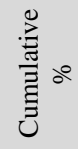 & \\
\hline 1 & 3.9 & 48.8 & 48.8 & 3.9 & 48.8 & 48.8 & 3.293 \\
\hline 2 & 1.4 & 18.0 & 66.8 & 1.4 & 18.0 & 66.8 & 3.104 \\
\hline
\end{tabular}

Furthermore, the scree plot test technique was used to confirm the number of components to retain.

Fig. 9 shows a scree plot of important eight (8) identified criteria. It clearly shows that there is a significant drop in eigenvalue between component 2 and component 3 . Also, there are two components with eigenvalues greater than one shown in scree plot. Therefore, the two principal components associated with an eigenvalue higher than 1.0 are retained for further analysis. 


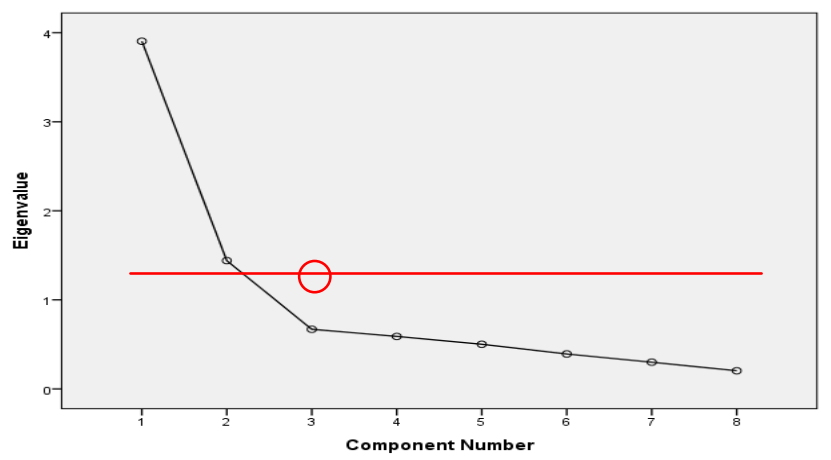

Fig. 9 Scree Plot Test

\section{- Rotation of the Factors}

In the rotating step of PCA, factor rotation is performed to rotate factor loadings for easier interpretation. The Oblique rotation technique was adopted for factor rotation using the Direct Oblimin Rotation.

TABLE shows rotated component loadings (eigenvectors) of confirmed two components. From this table, the first component concerned four criteria, which are Reducible Waste Structural Material, Reusable Structural Material, Recyclable Structural Material, and Durable Structural Material. While the second component concerned four criteria, which are Enhanced Structural Efficiency, Enhanced Production Process, Enhanced Design Approach, and Enhanced Thermal Mass. The first component is named enhanced materials. Whereas, the second component is named enhanced technique.

TABLE VI

ROTATED FACTOR LOADINGS OF THE TWO FACTORS EXTRACTED

\begin{tabular}{|l|l|c|c|}
\hline \multirow{2}{*}{ Criteria } & \multicolumn{2}{c|}{ Component } \\
\cline { 3 - 4 } & $\mathbf{1}$ & $\mathbf{2}$ \\
\hline 1 & Reducible waste structural material & .927 & \\
\hline 2 & Reusable structural material & .843 & \\
\hline 3 & Recyclable structural material & .805 & \\
\hline 4 & Durable structural material & .702 & \\
\hline 5 & Enhanced structural efficiency & & .831 \\
\hline 6 & Enhanced production process & & .809 \\
\hline 7 & Enhanced design approach & & .801 \\
\hline 8 & Enhanced thermal mass & & .704 \\
\hline
\end{tabular}

Based on a principal component analysis, eight selection criteria were grouped into two main factors; Enhanced Material factor, and Enhanced Design Technique factor. This suggested that the engineers seem to put the Enhanced Material and Enhanced Technique factors as a priority when assessing the structural building systems. These findings were in line with suggestions from the previous studies, which indicates that reducing embodied energy depends upon the choice of building materials as well as construction technique [40].

\section{CONCLUSION}

The selection of building components particularly the structural components directly affects the level of energy consumption throughout building life cycle. To select the energy efficient building structural components, there is a needs to identify the critical energy efficiency factors. In this study, the critical energy efficiency factors are presented and discussed. The critical energy efficiency criteria were identified using Principal Component Analysis (PCA). Based on this analysis, eight energy efficiency criteria were considered as critical criteria which grouped in two factors. The first factor consists of four energy efficiency criteria, namely Reducible Structural Material, Reusable Structural Material; Recyclable Structural Material, and Durable Structural Material. The second factor contains four energy efficiency criteria including Enhanced Design Approach, Enhanced Structural Efficiency, Enhanced Production Process; and Enhanced the Thermal Mass. This two factor recommends that the engineers should put their consideration on enhanced material and enhanced technique as a top priority for decision-making process for selecting energy efficient structural systems.

\section{REFERENCES}

[1] Kassem, M. et al., 2012. A Decision Support System for the Selection of Curtain Wall Systems at the Design Development Stage. Construction Management and Economics. 30(12): 1039-1053.

[2] Zhang, S. X. and Babovic, V. 2011. An Evolutionary Real Options Framework for the Design and Management of Projects and Systems with Complex Real Options and Exercising Conditions. Decision support systems. 51(1): 119-129.

[3] Mydin, S. H. et al., 2011. Buildability Attributes at Design Phase in Malaysian Building Construction. International Journal of Sustainable Construction Engineering and Technology. 2(1).

[4] Nourbakhsh, M. et al., 2012. A Conceptual Model to Assess the Buildability of Building Structure at Design Stage in Malaysia. Advanced Materials Research. 446446 (44): 3879-3884.

[5] Baharetha, S. M. 2013. A model for selecting sustainable exterior wall building materials; products in hot, humid climate. Dhahran 34464 31261, Saudi Arabia. King Fahd University of Petroleum and Minerals.

[6] Medineckiene, M. et al., 2015. Multi-criteria decision-making system for sustainable building assessment/certification. Archives of Civil and Mechanical Engineering. 15(1): 11-18.

[7] Yang, J. and Ogunkah, I. C. B. 2013. A multi-criteria decision support system for the selection of low-cost green building materials and components. Journal of Building Construction and Planning Research. 1(04): 89.

[8] Deniz, O. S. and Ekinci, S. 2016. A Decision-Making Process for Selecting Building Envelope Assemblies. Journal of Asian Architecture and Building Engineering. 15(3): 549-555.

[9] Saadah, Y. and Abuhijleh, B. 2010. Decreasing CO2 Emissions and Embodied Energy during the Construction Phase Using Sustainable Building Materials. International Journal of Sustainable Building Technology and Urban Development. 1(2): 115-120.

[10] Thormark, C. 2006. The Effect of Material Choice on the Total Energy Need and Recycling Potential of a Building. Building and Environment. 41(8): 1019-1026.

[11] Cole, R. J. 1998. Energy and Greenhouse Gas Emissions Associated with the Construction of Alternative Structural Systems. Building and Environment. 34(3): 335-348.

[12] Dodoo, A. et al., 2012. Effect of thermal mass on life cycle primary energy balances of concrete- and a wood-frame building. Applied Energy. 92: 462-472.

[13] Karimpour, M. et al., 2014. Minimising the Life Cycle Energy of Buildings: Review and Analysis. Building and Environment. 73(0): 106-114. 
[14] Blengini, G. A. 2009. Life Cycle of Buildings, Demolition, and Recycling Potential: A Case Study in Turin, Italy. Building and Environment. 44(2): 319-330.

[15] Shafiq, N. et al., 2015. Reduction of Embodied CO2 Emissions from Conventional Single Storey House in Malaysia by Recycled Materials Using Building Information Modeling (BIM). Advances in Environmental Biology. 9(1): 17-22.

[16] Chen, Y. et al., 2010. Sustainable Performance Criteria for Construction Method Selection in Concrete Buildings. Automation in construction. 19(2): 235-244.

[17] Sattary, S. and Thorpe, D. 2011. Reducing Embodied Energy in Australian Building Construction 27th Annual Conference of the Association of Researchers in Construction Management. pp. 10551064. Bristol, UK. Association of Researchers in Construction Management.

[18] Olomolaiye, P. O. et al., 2013. Multi-Criteria Evaluation Model for the Selection of Sustainable Materials for Building Projects. Automation in Construction. 30: 113-125.

[19] Dissanayake, D. and Jayasinghe, C. 2015. Embodied Energy Analysis of a Pre-cast Building System 6th International Conference on Structural Engineering and Construction Management Kandy, Sri Lanka

[20] Bakhoum, E. S. and Brown, D. C. 2013. A Hybrid Approach Using AHP-TOPSIS-Entropy Methods for Sustainable Ranking of Structural Materials. International Journal of Sustainable Engineering. 6(3): 212-224.

[21] Yunus, R. and Yang, J. 2014. Improving Ecological Performance of Industrialized Building Systems in Malaysia. Construction Management and Economics. 32(1-2): 183-195.

[22] Mao, C. et al., 2013. Comparative Study of Greenhouse Gas Emissions Between Off-Site Prefabrication and Conventional Construction Methods: Two Case Studies of Residential Projects. Energy and Buildings. 66: 165-176.

[23] Guggemos, A. A. and Horvath, A. 2005. Comparison of Environmental Effects of Steel-And Concrete-Framed Buildings. Journal of infrastructure systems. 11(2): 93-101.

[24] Johnson, T. W. 2006. Comparison of Environmental Impacts of Steel and Concrete as Building Materials Using the Life Cycle Assessment Method. Cambridge. Massachusetts Institute of Technology.

[25] Yun, Z. 2013. Decision Support System for the Selection of Structural Frame Material to Achieve Sustainability and Constructability. 21 Lower Kent Ridge Rd, Singapore. The National University Of Singapore.
[26] Xing, S. et al., 2008. Inventory Analysis of LCA on Steel- and Concrete-Construction Office Buildings. Energy and Buildings. 40(7): 1188-1193.

[27] Heravi, G. et al., 2016. Evaluation of Energy Consumption During Production and Construction of Concrete and Steel Frames of Residential Buildings. Energy and Buildings. 130: 244-252.

[28] Cuadrado, J. et al., 2015. Sustainability-related decision-making in industrial buildings: an AHP analysis.).

[29] Johanson, G. A. and Brooks, G. P. 2009. Initial Scale Development: Sample Size for Pilot Studies. Educational and Psychological Measurement).

[30] Saunders, M. N. K. et al., 2016. Research Methods for Business Students. (Edinburgh Gate, Harlow, Essex CM20 2JE, England. Pearson Education Limited)

[31] Syed Iskandar, B. S. I. et al., 2014. An Investigation of Level, Sources of Occupational Stress and Coping Strategies among Civil Engineers in Malaysia's Construction Industry. Australian Journal of Basic \& Applied Sciences. 8(17): 257-264

[32] Kish, L. 1965. Survey Sampling. (New York. Chichester. Brisbane. Toronto. John Wiley \& Sons, Inc.).

[33] Creswell, J. W. 2012. Educational Research: Planning, Conducting and Evaluating Quantitative and Qualitative Research. (Boston; Montréal. Pearson).

[34] Anderson, C. J. 2015. Principal Components Analysis [Powerpoint slides]. The University Of Illinois At Urbana-Champaign.

[35] Brown, J. D. 2009. Principal Components Analysis and Exploratory Factor Analysis-Definitions, Differences, and Choices. JALT Testing \& Evaluation SIG Newsletter. 13(1): 26-30.

[36] Vukotic, L. et al., 2010. Assessing Embodied Energy of Building Structural Elements. Proceedings of the ICE-Engineering Sustainability. 163(3): 147-158.

[37] Elliott, A. C. and Woodward, W. A. 2007. Statistical Analysis Quick Reference Guidebook: With SPSS Examples. (the United States of America. Sage).

[38] Kaiser, H. F. 1970. A Second Generation Little Jiffy. Psychometrika. 35(4): 401-415.

[39] Pallant, J. 2016. SPSS Survival Manual: A Step by Step Guide to Data Analysis Using IBM SPSS 6th edition (Midland Typesetters, Australia. Allen \& Unwin).

[40] Reddy, B. V. and Jagadish, K. 2003. Embodied Energy of Common and Alternative Building Materials and Technologies. Energy and Buildings. 35(2): 129-137. 